\title{
Simulation of the climate impact of Mt. Pinatubo eruption using ECHAM5 - Part 1: Sensitivity to the modes of atmospheric circulation and boundary conditions
}

\author{
M. A. Thomas ${ }^{1}$, C. Timmreck ${ }^{1}$, M. A. Giorgetta ${ }^{1}$, H.-F. Graf ${ }^{2}$, and G. Stenchikov ${ }^{3}$ \\ ${ }^{1}$ Max-Planck-Institut for Meteorology, Hamburg, Germany \\ ${ }^{2}$ Center for Atmospheric Sciences, Cambridge University, UK \\ ${ }^{3}$ Department of Environmental Sciences, Rutgers - The State University of New Jersey, USA
}

Received: 12 March 2008 - Published in Atmos. Chem. Phys. Discuss.: 22 May 2008

Revised: 20 August 2008 - Accepted: 21 October 2008 - Published: 29 January 2009

\begin{abstract}
The eruption of Mt. Pinatubo in the Philippines in June 1991 was one of the strongest volcanic eruptions in the 20th century and this well observed eruption can serve as an important case study to understand the subsequent weather and climate changes. In this paper, the most comprehensive simulations to date of the climate impact of Mt. Pinatubo eruption are carried out with prescribed volcanic aerosols including observed SSTs, QBO and volcanically induced ozone anomalies. This is also the first attempt to include all the known factors for the simulation of such an experiment. Here, the climate response is evaluated under different boundary conditions including one at a time, thereby, investigating the radiative and dynamical responses to individual and combined forcings by observed SSTs, QBO and volcanic effects. Two ensembles of ten members each, for unperturbed and volcanically perturbed conditions were carried out using the middle atmosphere configuration of ECHAM5 general circulation model. Our results show that the simulated climate response that may arise solely from aerosol forcing in lower stratospheric temperature is insensitive to the boundary conditions in the tropics and does not show some observed features such as the temperature signature of the QBO phases. Also, statistically significant positive anomalies in the high latitudes in $\mathrm{NH}$ winter of 1991/92 seen in our model simulations with prescribed observed SST and QBO phases as boundary conditions are consistent with the observations. To simulate realistically the lower stratospheric temperature response, one must include all the known factors. The pure QBO and ocean signatures in lower stratospheric temperature are simulated con-
\end{abstract}

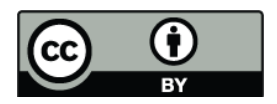

Correspondence to: M. A. Thomas (manu.thomas@zmaw.de) sistently with earlier studies. The indirect effect of the volcanic aerosols manifested as the winter warming pattern is not simulated in the ensemble mean of the experiments. Our analysis also shows that the response to El Niño conditions is very strong in the model and that it partially masks the effects due to volcanic forcing.

\section{Introduction}

Large volcanic eruptions and their subsequent climate responses are relatively short-lived perturbations to the climate system. They provide an excellent opportunity to understand the response of the climate system to a global radiative forcing and to assess the ability of our climate models to simulate such large perturbations. The volcanic effects can be mostly divided into three - radiative, dynamical and chemical processes. The $\mathrm{SO}_{2}$ injected into the stratosphere by explosive volcanic eruptions is chemically transformed to sulfate aerosols and in the case of Mt. Pinatubo eruption, encircled the globe in a month (McCormick and Veiga, 1992; Long and Stowe, 1994). Sulfate aerosol particles are purely scattering in the visible part of the solar spectrum, thus scattering the incoming solar radiation partially back to space, resulting in cooling of the Earth surface. After the Pinatubo eruption a reduction of the amount of solar radiation reaching the Earth's surface (Dutton and Christy, 1992; Minnis et al., 1993) and lower temperatures in the troposphere (Dutton and Christy, 1992; Jones et al., 2003) have been observed. In the near infrared (IR) and in the IR, sulfate aerosols are good absorbers, thus warming the aerosol layers significantly by a few degrees depending on the amount of aerosol. However, the effects of QBO and amount of ozone depleted due

Published by Copernicus Publications on behalf of the European Geosciences Union. 
to heterogeneous chemical reactions cools the aerosol layer, but, the net effect is still heating. The Pinatubo volcanic aerosol particles produce significant warming in the lower equatorial stratosphere (Timmreck et al., 1999; Robock and Mao, 1995) thereby increasing the equator to pole temperature gradient in the lower stratosphere of the winter hemisphere changing atmospheric circulation patterns (Graf et al., 2007; Stenchikov et al., 2002) and forcing an anomalously positive phase of the Arctic Oscillation (Robock and Mao, 1992, 1995; Perlwitz and Graf, 1995). This is manifested at the surface as a winter warming pattern in the $\mathrm{NH}$ high latitude continents, which is typical of low latitude eruptions. It has to be noted that the three largest eruptions in the last 50 years (Agung, El Chichõn and Pinatubo) occurred in conjunction with a strong El Niño event in the Pacific. Christiansen (2008) analyzed 13 volcanic eruptions and showed that the impact of volcanic eruptions in the $\mathrm{NH}$ winter circulation does not depend on the phase of El Niño-Southern Oscillation (ENSO) and both the AO and NAO (North Atlantic Oscillation) modes are excited during the first winters after the volcanic eruptions.

The circulation in the lower atmosphere can be affected by short term stratospheric perturbations, for example, ozone changes (Rind et al., 1992; Grainger et al., 1993; Kodera, 1994; Randel et al., 1995; Timmreck et al., 2003). It is thus interesting to explore the various ways in which the stratospheric perturbations can influence the tropospheric circulation. The variability in the stratosphere is mainly due to anomalous boundary forcings or natural internal variations. Natural internal variability mainly arises from the non linearity of the dynamics of the circulation in the middle atmosphere. Boundary forcing arises from variations in the tropospheric forcing such as changes in radiative budget due to changes in atmospheric composition e.g. ozone depletion via volcanic aerosols/anthropogenic influences or re-distribution of tropical heat sources such as the ENSO events. This can in turn give rise to changes in vertically propagating wave disturbances (Holton, 1982; Matsuno, 1970; Manzini et al., 2006). But, in the real world, where the circulation evolves under the continuous influence of a combination of factors, it is not simple to determine the responses to single influencing factors. For example, it is not possible to isolate the ENSO effects from other elements of natural variability if the signal is small and is strongly varying because of internal variability (Hamilton, 1993; Baldwin and Sullivan, 1995). However, it is possible to do so using a numerical model, for example, where ENSO is the only specified source of variability in addition to internal model dynamics and other surface properties like snow cover or soil moisture, which are computed by the model.

The observed climate evolution following a major volcanic eruption has significant anomalies compared to climatology. These have, however, occurred under additional influences of sea surface temperature (SST) anomalies (e.g. the major explosive volcanic eruptions of the last 50 years coin- cided with an El Niño) and the specific phases of the QuasiBiennial Oscillation (QBO) and possibly other influences. Hence while simulating this impact, one must consider all these interactions. Many of the previous studies that simulated the climate impact of Mt. Pinatubo eruption considered only one or the other of the forcings, thus resulting in incomplete interpretation of the results. For example, Kirchner et al. (1999) and Ramachandran et al. (2000) studied the climate response to Mt. Pinatubo eruption and its sensitivity to SSTs, neglecting the effects of QBO and ozone changes. Their model simulations reproduced the lower stratospheric temperature response realistically in the tropics, but in the study by Kirchner et al. (1999), the dynamical response was weakly simulated under climatological SST as boundary conditions. Several studies were made by Stenchikov et al. $(1998,2002,2006)$ to understand the climate response to Mt. Pinatubo eruption, but, all these studies did not incorporate all the known factors that may have influenced the observed anomalies. In this paper, the generalized climatic response to Mt. Pinatubo eruption with different boundary conditions and forcings is examined. The responses of the tropospheric and stratospheric circulation to individual and combined factors including volcanic forcing, varying SST boundary conditions and different states of the QBO are assessed. This is important as this gives us insights on how climate responds to the radiative forcing of the observed Mt. Pinatubo eruption, in which either one or more of the concurrent forcings such as the El Niño sea surface anomalies, the QBO phase are included.

As mentioned before, none of the simulations carried out so far included all the important factors together for the simulation of Mt. Pinatubo eruption. Hence, this study tries to simulate the response to this huge natural perturbation by including all the known factors and additionally, analyze the response to individual and combined forcings using the same model set up. As the different phases of the QBO have different effects on the stratospheric circulation, the climate impact after Pinatubo eruption in the opposite QBO phase is also evaluated in a separate paper (Thomas et al., 2008b). This paper is the first of a two part series where the following main scientific questions are addressed

1. What is the climate effect that arises solely as a result of volcanic radiative forcing and how does this effect vary under different boundary conditions?

2. What is the climate response to combined influences of Mt. Pinatubo volcanic eruption and other boundary condition changes?

We will focus in our study on the lower stratospheric temperature response and the boreal winter high latitude response in surface temperature and geopotential height at $30 \mathrm{hPa}$. 


\section{Model and datasets used}

\subsection{Model description}

The most recent version of the fifth generation atmospheric general circulation model ECHAM5 developed at the Max Planck Institute for Meteorology, Hamburg (Special section "Climate models at the Max-Planck Institute for Meteorology" in Journal of Climate, 19(16), 3769-3987, 2006) is used at T42 horizontal resolution and with 39 vertical layers, topmost layer at $0.01 \mathrm{hPa}$ (Manzini et al., 2006). Since radiative transfer is the major process linking the general circulation to volcanic aerosols in the stratosphere, the radiation schemes in both shortwave (SW) and longwave (LW) are mentioned briefly here. The SW radiative transfer scheme of ECHAM5 is based on the scheme by Fouquart and Bonnel (1980) and the LW radiative transfer follows the RRTM (Rapid Radiative Transfer Model) scheme (Mlawer et al., 1997) as implemented in cycle 23 release 1 of the IFS model of ECMWF (Morcrette et al., 1998). The number of spectral bands in the shortwave has been increased from 4 to 6 and the range expanded from $[0.250-4.00 \mu \mathrm{m}]$ to [0.185-4.00 $\mu \mathrm{m}]$ (Cagnazzo et al., 2007). Both the Near IR and the UV/VIS spectral range is resolved by three bands each to account better for the wavelength dependencies of optical properties of aerosols. Additionally the original shortwave code has been generalized for large optical thicknesses of volcanic sulphate aerosol layers in the stratosphere as necessary for the aerosol loading after Mt. Pinatubo eruption. This improvement is documented in Thomas (2007).

The radiative transfer calculations are made every two hours using temperature, cloud, water vapour, etc of the current time and solar zenith angles for the middle of the following two hour interval. While longwave fluxes are kept constant over the two hour interval, shortwave fluxes are linearly corrected by the local cos(zenith angle) at each $15 \mathrm{~min}$ time step in the two hour interval with respect to the local cos(zenith angle) in the middle of the two hour interval, and shortwave fluxes are set to zero during night time. The radiative transfer calculation requires profiles of active gases, aerosols, cloud water and ice and cloud cover. Water vapor, cloud water and ice are prognostic variables. $\mathrm{CO}_{2}\left(348 \times 10^{-6}\right), \mathrm{CH}_{4}\left(1.65 \times 10^{-6}\right), \mathrm{N}_{2} \mathrm{O}\left(306 \times 10^{-9}\right)$ and CFCs (for CFC-11 and CFC-12, the volume mixing ratios are $280 \times 10^{-12}$ and $484 \times 10^{-12}$, respectively) are prescribed with a constant volume mixing ratio, and ozone is prescribed as the zonally averaged monthly climatology of Fortuin and Kelder (1998) which is based on the observation over a period 1980-1991. Background aerosol distributions are prescribed following Tanre et al. (1984). This climatology distinguishes spatial distributions of sea, land, urban and desert aerosols and well mixed tropospheric and stratospheric background aerosols.

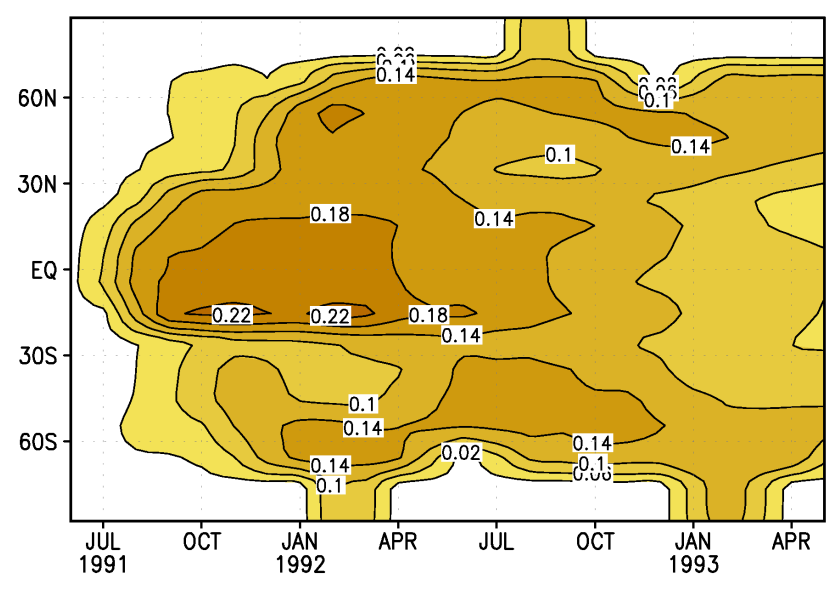

Fig. 1. Zonally averaged Pinatubo aerosol optical depth at $0.55 \mu \mathrm{m}$ for two years after the eruption.

\subsection{Datasets}

For the volcanic aerosol forcing, Pinatubo aerosol data that have been compiled by G. Stenchikov from SAGE II (Stratospheric Aerosol and Gas Experiment) and UARS (Upper Atmosphere Research Satellite) satellite data for the specific model resolution is used. The retrievals at $0.55 \mu \mathrm{m}$ are used to calculate the aerosol parameters as the conventions in Sato et al. (1993). The aerosol dataset consists of zonally averaged values of extinction cross section, single scattering albedo and asymmetry factor for two years following the Pinatubo eruption. The aerosol optical depth at $0.55 \mu \mathrm{m}$ for two years after the eruption is shown in the Fig. 1. The spread of the volcanic aerosol cloud is clearly evident.

The ozone anomalies owing to Mt. Pinatubo eruption were compiled by Stenchikov et al. (2002) from in-situ ozonesonde observations and are validated using TOMS (Total Ozone Mapping Spectrometer) column observations (Randel et al., 1995). To produce the ozone data set for our simulations, the monthly mean and zonal ozone anomalies are first interpolated to the model grid and then applied to the zonal mean ozone distribution used in ECHAM5. The zonally averaged ozone anomalies used in this study at $20 \mathrm{hPa}$ for two years following the eruption is shown in the Fig. 2 . There is a maximum ozone loss of up to $1.2 \mu \mathrm{g} / \mathrm{g}$ in the tropics and up to $0.7 \mu \mathrm{g} / \mathrm{g}$ in the polar regions. Maximum ozone loss occurs in the winter hemispheres with losses of up to $0.7 \mu \mathrm{g} / \mathrm{g}$ in SH and up to $0.4-0.5 \mu \mathrm{g} / \mathrm{g}$ in $\mathrm{NH}$ at $20 \mathrm{hPa}$. Positive ozone anomalies are visible in the equatorial region from December 1992 during the westerly QBO phase. The total column ozone loss exceeded 50 Dobson Units (DU) in middle and high latitude in NH winter and spring of 1992 and 1993. However, in the equatorial region, there is a total column ozone loss of up to $15 \mathrm{DU}$ in the first year after the eruption and an increase of up to 5 DU in January 1993 (Stenchikov et al., 2002). 


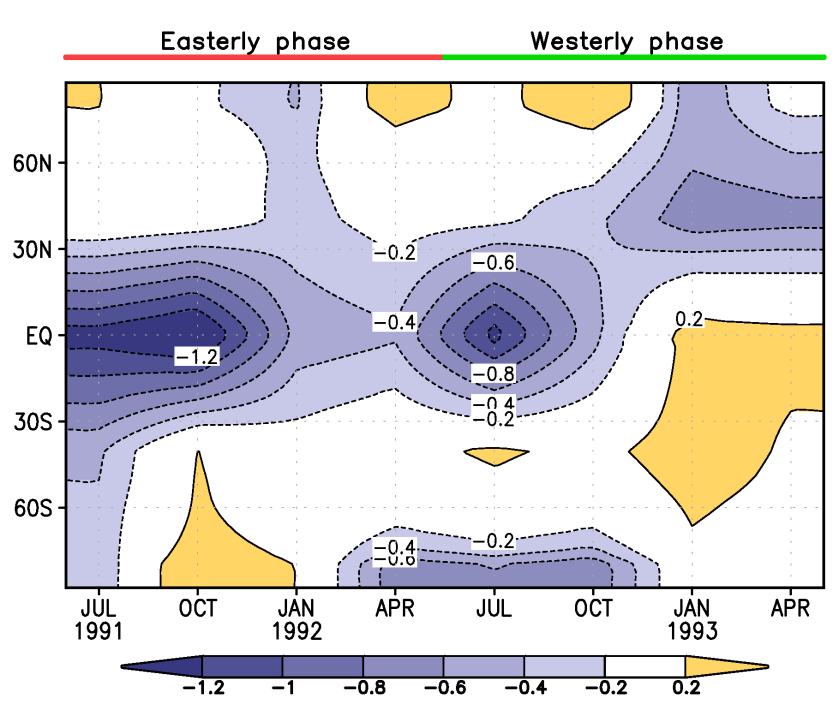

Fig. 2. Zonally averaged volcanically induced ozone anomalies at $20 \mathrm{hPa}$ in $(\mu \mathrm{g} / \mathrm{g})$ for two years after the eruption. Contours are at $0.2 \mu \mathrm{g} / \mathrm{g}$ intervals. The easterly and westerly phase of the QBO during this period is also shown as the color bars at the top of the plot.

Table 1. Perturbed and unperturbed ensemble experiments. The subscript " $u$ " is used to denote the unperturbed runs and " $p$ " is used for perturbed runs. C stands for climatological SST; O stands for observed SST; Q for QBO.

\begin{tabular}{l|c|c|c}
\hline Experiments & $\begin{array}{c}\text { Clim_SST } \\
(\mathrm{C})\end{array}$ & $\begin{array}{c}\text { Obs_SST } \\
(\mathrm{O})\end{array}$ & $\begin{array}{c}\text { O_QBO } \\
(\mathrm{OQ})\end{array}$ \\
\hline $\begin{array}{l}\text { Unperturbed runs } \\
\text { Perturbed runs }\end{array}$ & $\mathrm{C}_{u}$ & $\mathrm{O}_{u}$ & $\mathrm{OQ}_{u}$ \\
$\mathrm{C}_{p}$ & $\mathrm{O}_{p}$ & $\mathrm{OQ}_{p}$ \\
\hline
\end{tabular}

Our results are validated with the ERA-40 fields. ERA-40 is a re-analysis of meteorological observations from September 1957 to August 2002 produced by the European Center for Medium Range Weather Forecasts (ECMWF) in collaboration with many institutions (Uppala et al., 2005). In this paper, the monthly data for 43 years from January 1958 to December 2001 are used for the computation of the mean climatology. The anomalies are calculated as a difference of the fields for the Pinatubo period (June 1991-May 1993) from the mean climatology. It has to be noted that Pinatubo eruption is only one volcanic event and so, the observations correspond to only one member of the PDF (Probability Distribution Function). In order to validate the simulated fields with the observations, one should consider at least a significant number of similar volcanic events. However, it has to be mentioned that the $\mathrm{NH}$ winter surface temperature anomalies and the strengthening of the polar vortex is a robust feature after tropical explosive volcanic eruptions such as Agung, El Chichõn and Mt. Pinatubo (Thomas, 2007).

\section{Experimental set up}

The ensembles of perturbed and unperturbed runs carried out for two years following the Mt. Pinatubo eruption from June 1991-May 1993 with different boundary conditions are presented in Table 1. The perturbed runs include the zonally and monthly averaged prescribed volcanic aerosol distribution and volcanically induced ozone anomalies. The subscript " $u$ " is used to denote the unperturbed runs and " $p$ " for the corresponding perturbed runs. Runs are carried out with climatological SST (Clim_SST), observed SST (Obs_SST) and with boundary conditions combining observed SST and the observed QBO phase (O_QBO).

For each experimental set up of Table 1, an ensemble of 10 runs is carried out. In the perturbed experiments with climatological SST and sea ice conditions $\left(\mathrm{C}_{p}\right)$, the initial conditions are chosen arbitrarily from the 15 -year control run simulation with climatological SST and sea ice (SIC) distribution $\left(\mathrm{C}_{u}\right)$ after spin up. Thus, we have ten independent realizations. The ensemble mean response is calculated as an average difference of the ensemble mean, $\mathrm{C}_{p}$ of the perturbed runs and the unperturbed run mean, $\mathrm{C}_{u}$.

Similarly, ensemble runs have been performed with observed SST and SIC as boundary conditions (from Atmospheric Model Intercomparison Project, Gates, 1992). Ten two-year experiments are carried out with Pinatubo aerosol forcing and ozone forcing (perturbed run) and without them (unperturbed run). For both cases, the initial conditions are taken from the 15 year control run carried out with climatological SST and SIC as boundary conditions and a spin up of 17 months using the observed lower boundary conditions of Jan 1990 to May 1991 is made before the beginning of the perturbed and unperturbed runs. The response in this case is calculated as a one-to-one difference of the ensemble means of the perturbed and the unperturbed ensembles, $\mathrm{O}_{p}$ and $\mathrm{O}_{u}$, respectively.

For the runs including the QBO, a similar procedure as above is adopted. In this case, a spin up of 17 months is carried out with observed SST and with the observed QBO phase. This experiment includes the 1991/92 El Niño induced SST anomalies that coincided with this eruption. To include the QBO forcing in this study, the zonal winds in the tropics are nudged towards the zonal wind observations at Singapore (Giorgetta and Bengtsson, 1999). The nudging is applied uniformly in a core domain and extends with decreasing nudging rate to the boundary of the domain. The latitudinal core domain specified for the study here is $7^{\circ} \mathrm{N}-$ $7^{\circ} \mathrm{S}$ and the domain boundary is $10^{\circ} \mathrm{N}-10^{\circ} \mathrm{S}$. In the vertical the core domain and the boundary is over the levels extending from $70 \mathrm{hPa}$ to $10 \mathrm{hPa}$. The nudging rate is $(10 \text { days })^{-1}$. Hence, the nudging interferes with the dynamics in this well defined domain only on time scales of 10 days and longer. Practically this means that only zonal wind features of timescales longer than 10 days are directly influenced by the nudging scheme. The QBO signals in meridional and 
vertical wind or temperature within the nudging domain, or the QBO signals outside the nudging domain result from the primitive equation dynamics of the model.

The ensemble runs can be analyzed in different ways as shown in Table 2 to obtain ensemble mean responses for specific forcing differences. The boxes show the differences between the corresponding perturbed ensemble (in the row) and the unperturbed control ensemble (in the column). For example, Aer1 is the ensemble mean difference $\mathrm{C}_{p}-\mathrm{C}_{u}$ and Aer+O+QBO is the difference $\mathrm{OQ}_{p}-\mathrm{C}_{u}$. Hence, Aer1, Aer2 and Aer3 give the simulated climate response to aerosol forcing under different boundary conditions. So, Aer1 gives the response under climatological SST as boundary conditions, Aer2 the response under observed SST (El Niño effects of 1991/92) as boundary conditions and Aer3 under both observed SST and QBO. The table also gives the responses to individual forcing differences of the ocean $(\mathrm{O})$ and $\mathrm{QBO}$ (Q). The other responses discussed in this chapter are (1) the combined aerosol and ocean forcing (AO), (2) the combined aerosol and QBO forcing (AQ) and (3) the combined aerosol, ocean and QBO forcing (AOQ).

The main advantage of these experiments is that it is possible to isolate the effects of volcanic aerosol, the ocean and the QBO and also assess their combined effects so as to better understand the observed responses.

\section{Results and discussion}

A comparison of the different forcing experiments in simulating the tropical and high latitude response to the Mt. Pinatubo eruption is discussed. In this paper, we choose the stratospheric temperature to characterize the direct aerosol radiative effects and $30 \mathrm{hPa}$ geopotential and $2 \mathrm{~m}$ temperature to analyze the circulation response in the winters following Mt. Pinatubo eruption.

\subsection{Stratospheric temperature response}

The Pinatubo volcanic plume reached a maximum height of $40 \mathrm{~km}$ (Lynch and Stephens, 1996; Holasek et al., 1996), with the bulk of aerosol centered around $25 \mathrm{~km}$. Hence, in this section the simulation of the temperature response at $30 \mathrm{hPa}$ to the Pinatubo aerosol forcing is discussed by means of the different forcing experiments. The simulated responses are presented in Fig. 3a-i and the observed response from ERA40 is shown in Fig. 3j.

As mentioned in the previous section, Aer1 and Aer2 give the simulated climate responses to the volcanic aerosol forcing for different SST boundary conditions (Table 1). Hence, Aer1 is the aerosol response for climatological SSTs, whereas Aer2 is the aerosol response where the boundary condition includes SST and ice of 1991-1993 including the effects of El Niño. In Fig. 3a and b, the tropical responses are similar in pattern, but the response is slightly higher with
Table 2. Ensemble mean differences between perturbed and unperturbed runs. The text in bold are the difference between the corresponding perturbed runs and unperturbed control runs.

\begin{tabular}{c|c|c|c|c|c}
\hline \multicolumn{3}{c|}{ Unperturbed runs } & \multicolumn{3}{c}{ Perturbed runs } \\
\hline $\mathrm{O}_{u}$ & $\mathrm{C}_{u}$ & - & $\mathrm{C}_{p}$ & $\mathrm{O}_{p}$ & $\mathrm{OQ}_{p}$ \\
\hline & & $\mathrm{C}_{u}$ & Aer1 & $\begin{array}{c}\text { Aer+O } \\
(\mathbf{A O})\end{array}$ & $\begin{array}{c}\text { Aer+O+QBO } \\
\text { (AOQ) }\end{array}$ \\
\hline & $\begin{array}{c}\text { Ocean } \\
(\mathbf{O})\end{array}$ & $\mathrm{O}_{u}$ & & $\mathbf{A e r 2}$ & $\begin{array}{c}\text { Aer+QBO } \\
(\mathbf{A Q})\end{array}$ \\
\hline $\begin{array}{c}\text { QBO } \\
(\mathbf{Q})\end{array}$ & $\begin{array}{c}\mathbf{Q B O + O} \\
(\mathbf{O Q})\end{array}$ & $\mathrm{OQ}_{u}$ & & & Aer3 \\
\hline
\end{tabular}

observed SST as boundary conditions, with a maximum of up to $3 \mathrm{~K}$. The magnitude of the response is well simulated when compared to the observations (Fig. 3j) showing that the anomalies are clearly linked with the eruption. Both ENSO and QBO are prescribed as boundary conditions in the runs of Aer3 (Fig. 3c). The tropical response in Aer3 remains more or less the same as Aer1 and Aer2 simulations, different from the well structured observed anomalies. The response for Aer1, Aer2 and Aer3 in the latitudinal belt of $50^{\circ} \mathrm{N}-50^{\circ} \mathrm{S}$ is statistically significant at the $99 \%$ significance level from August 1991 to April 1993 (not shown). The main point to be noted here is that the warming during the period January 1992-April 1992 in the Northern Hemisphere (NH) high latitudes in Aer3 corresponding to the weak polar vortex is consistent with observations (Fig. 3j) and is statistically significant at 95\% confidence level (not shown), with temperatures reaching as high as $7 \mathrm{~K}$, whereas, this signal is much weaker and is not significant in Aer1 and Aer2. The large anomalies in the SH springtime high latitudes in the observations (Fig. 3j) are not simulated in these experiments.

Before analyzing the responses to combined forcings, it is important to analyze the ocean $(\mathrm{O})$ and $\mathrm{QBO}(\mathrm{Q})$ alone ensemble differences to see whether the model reproduces the effect of El Niño and QBO circulation realistically.

Figure $3 \mathrm{~d}$ accounts for the effects of El Niño alone. ENSO signal propagates into the middle atmosphere by means of planetary Rossby waves and this propagation is strong when the stratospheric winds are westerly and peaks during boreal winter in the mid-latitudes (Garcia et al., 2006). Studies by Sassi et al. (2004); Manzini et al. (2006); Chen et al. (2003) have shown that during an El Niño event, the enhancement of vertical propagation and divergence of E-P flux cools the tropics and warms the high latitudes. Figure $3 d$ shows a similar pattern for the period from January 1992 to July 1992 as in the literature and the anomalies are significant (not shown) except that the cooling in the tropics is less by $50 \%$ at $30 \mathrm{hPa}$. The cooling is more evident in the $50 \mathrm{hPa}$ temperature anomalies (not shown here). 

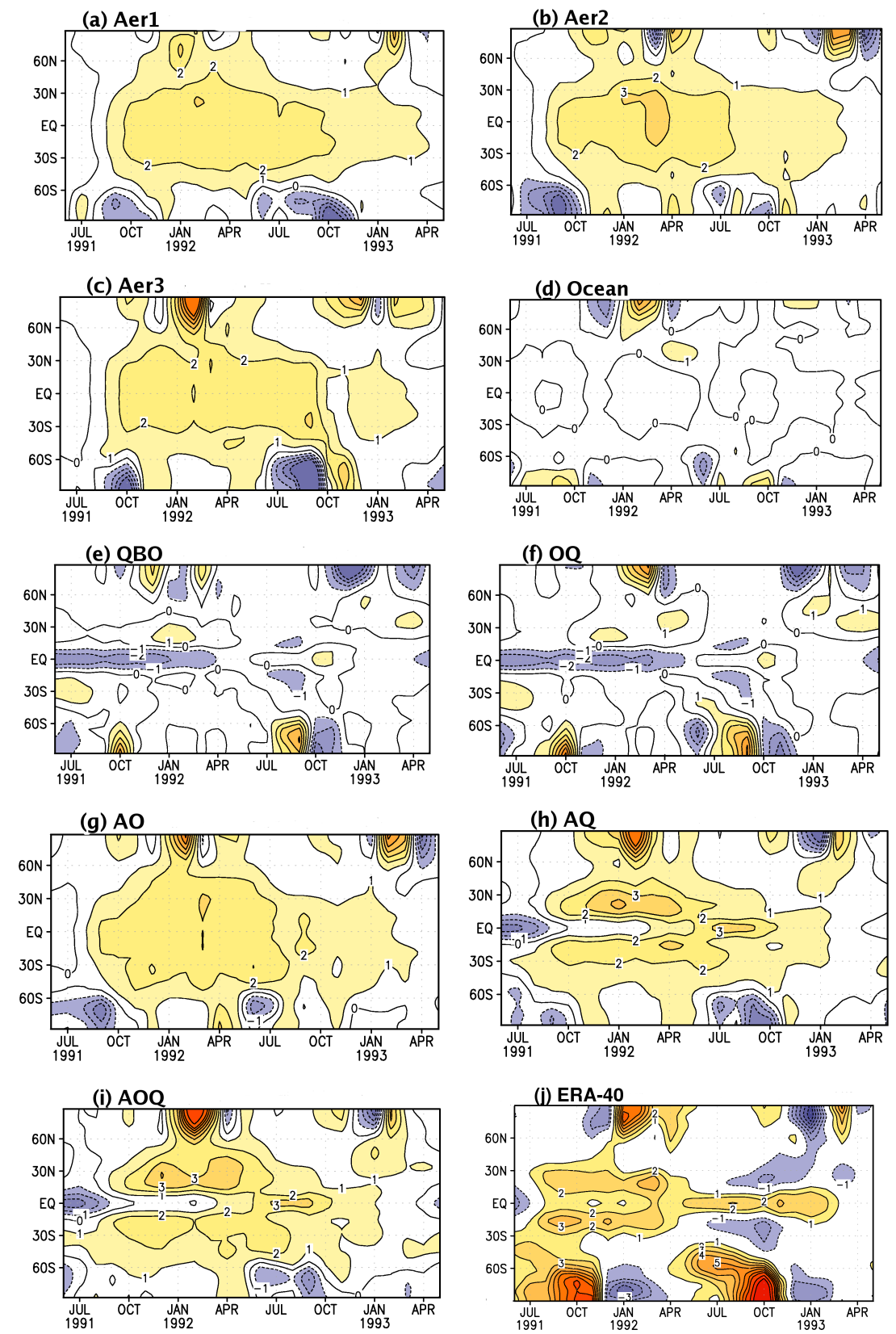

Fig. 3. Lower stratospheric temperature anomalies at $30 \mathrm{hPa}(K)$ for (a) Aer1 (b) Aer2 (c) Aer3 (d) ocean response (e) QBO response (f) combined ocean and QBO - OQ (g) combined aerosol and ocean - AO (h) combined aerosol and QBO - AQ (i) combined aerosol, ocean and QBO - AOQ (j) ERA-40. Contours are at $1 \mathrm{~K}$ intervals. The anomalies in the latitudinal belt of $50^{\circ} \mathrm{N}-50^{\circ} \mathrm{S}$ are statistically significant at $99 \%$ level from August 1991 to April 1993 for all the cases except (d) where the 99\% significance level is restricted to the period January 1992 to July 1992.

Figure 3e shows the QBO-related lower stratospheric temperature anomalies at $30 \mathrm{hPa}$. A cooling of about $1-2 \mathrm{~K}$ associated with the easterly phase of QBO is shown in the latitudinal belt from $15^{\circ} \mathrm{N}-15^{\circ} \mathrm{S}$ from June 1991 to June 1992 and warm anomalies in mid-latitudes. The opposite is seen during the westerly phase of QBO though the warming is only of about $0.5 \mathrm{~K}$. This asymmetry between strong cold and weak warm equatorial temperature anomalies at $30 \mathrm{hPa}$ results from the bias in climatological temperature of the reference simulation $\mathrm{O}_{u}$, which misses the long term net effects of the QBO (Punge and Giorgetta, 2008). Hence Fig. 3e shows a combination of this climatological bias in equatorial temperature at $30 \mathrm{hPa}$ of $\mathrm{O}_{u}$ and the actual phase related QBO signal evolving in $\mathrm{OQ}_{u}$ over the displayed time period. The 
resulting asymmetry of cold and warm equatorial anomalies at $30 \mathrm{hPa}$ (Fig. 3e) occurs also in Fig. 3h and i. In the latter case this is obvious in comparison with Fig. 3j of ERA-40, where the reference climatology includes the long term effects of the QBO (cf. Part II of this paper for more details on the role of the QBO phase). The QBO signature in the stratospheric temperature can also be seen in the other responses with QBO (Fig. 3e, f, h and i) and is consistent with previous studies (Baldwin et al., 2001). The response to combined ocean and QBO forcings is shown in Fig. 3f and the responses are linear except in high latitudes, which means that the tropical temperature response to combined ocean and QBO forcing is the sum of the temperature responses to single forcings by ocean and QBO.

The AO ensemble difference accounts for the effects of both aerosol and ocean (Fig. 3g). The maximum temperature anomaly of $2 \mathrm{~K}$ is simulated and here too, the anomalies are statistically significant at $99 \%$ level and the responses are linear in the tropics.

Figure $3 \mathrm{~h}$ is the $30 \mathrm{hPa}$ temperature response when both aerosol and QBO (AQ) effects are considered. The effect of easterly and westerly phase of QBO can be clearly seen. In the easterly phase, the AQ response shows a dual peak with relative maximum in the subtropics and a minimum at the equator and in the westerly phase, the AQ response shows a single equatorial peak. The significant warming beyond $60^{\circ} \mathrm{N}$ during the winter of 1991/92 and the cooling during the winter of $1992 / 93$ is not seen in the runs without the QBO and is consistent with observations. Comparing with the observed response as in Fig. 3j, the simulated response is most realistic when $\mathrm{A}, \mathrm{O}$ and $\mathrm{Q}$ forcings are included (Fig. 3i). There is not much difference between the AQ and AOQ, except that the high latitude response in first boreal winter is much stronger in AOQ. Though the NH high latitude response is realistically simulated, it has to be noted that large discrepancies exist in the southern hemisphere high latitudes in all the model simulations. Hence, our simulations show that in order to simulate the pattern and the magnitude of the observed lower stratospheric temperature anomalies realistically, it is best to include all three forcings, namely, volcanic radiative forcing, observed SST/ice and the correct QBO phase.

\subsection{Geopotential height response at $30 \mathrm{hPa}$}

In the two winters following the major eruptions, an anomalously positive AO index (Thompson et al., 1998; Baldwin and Dunkerton, 1999) is observed. This can be seen in Fig. $4 \mathrm{~s}$ and $\mathrm{t}$ calculated from ERA-40 re-analysis data after Mt. Pinatubo eruption. The vortex is much deeper in the second winter where the anomalies reach as low as $-350 \mathrm{~m}$ compared to the first winter, where the lowest value reached is $-150 \mathrm{~m}$. Figure $4 \mathrm{a}-\mathrm{r}$ shows the $30 \mathrm{hPa}$ geopotential height anomaly as a representative of the strength of the polar vortex for all the forcing experiments considered here. Of which, the left column is the response for the first winter and the right column is the response for the second winter following the eruption. The statistical significance is indicated by shading. Differences in heavily and lightly shaded areas are significant at the $99 \%$ and $90 \%$ confidence level, respectively. In both winters, the aerosol response simulated under climatological SST as boundary conditions (Fig. 4a and b) does not capture the magnitude and spatial pattern of the polar vortex (refer Fig. $4 \mathrm{~s}$ and $\mathrm{t}$ ). However, under observed SST as boundary conditions (Fig. 4c and d), the aerosol response shows an anomalously strong stratospheric polar vortex in the second winter that is consistent with the observations, but the anomaly is weaker and not statistically significant. The geopotential height anomaly reaches $-100 \mathrm{~m}$. Statistically significant negative geopotential anomalies are simulated in the second winter in Aer3 experiment (Fig. 4f), but the anomalies are weak and shifted to the East compared to the observations, whereas the vortex is disturbed in the first winter (Fig. 4e).

The ENSO effect on the winter circulation is shown in Fig. $4 \mathrm{~g}$ and $\mathrm{h}$. A dipole structure is seen with positive geopotential height anomalies over northern N. America and Russia and negative anomalies over northern Atlantic and Europe during the first winter, whereas in the second winter, the dipole is shifted clockwise, with positive anomalies over the pole and Siberia and negative geopotential height anomalies over the East coast of North America. During a warm ENSO, enhanced wave propagation in boreal winter disturbs the polar vortex (Sassi et al., 2004; Manzini et al., 2006).

In the westerly phase of the QBO the polar vortex is expected to be anomalously strong and in the easterly phase anomalously weak (Holton and Tan, 1980, 1982) in the absence of the aerosol effects. This is evident in the QBO experiment, where the QBO is the only source of variability (Fig. $4 \mathrm{i}$ and $\mathrm{j}$ ). Figure $4 \mathrm{j}$ shows that the geopotential height anomalies at high latitudes is lower reaching a minimum value $-140 \mathrm{~m}$ and is surrounded by positive anomalies in the second winter when the QBO is in its westerly phase.

The combined effects of ENSO and QBO (OQ) do not simulate a strong vortex in neither of the two winters (Fig. 4k and 1). This is because, during the first winter, neither ENSO nor the easterly phase of the QBO favors an anomalously strong polar vortex. But, during the second winter, with the ENSO effects relatively weak and with QBO in its westerly shear, the model still cannot produce a strong polar vortex, reflecting the non-linearity in the way QBO modulates the circulation. A dipole structure is observed with low values over Europe, Russia and the northern Atlantic and high values over Canada in the first winter and the opposite is observed in the second winter.

In the first winter (Fig. 4m), the vortex is shifted southward and is weak, whereas in the second winter (Fig. 4n), the vortex is disturbed for the combined aerosol and ocean (AO) forcing. The same is seen for the combined aerosol and QBO (AQ) forcing in the first winter (Fig. 4o). However, in 
(a) Aer1 - DJF 1991/92

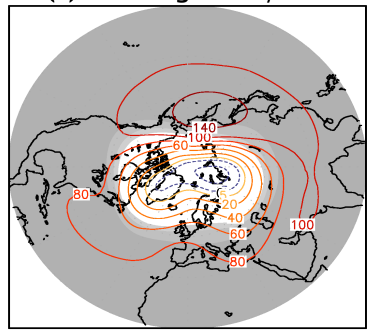

(c) Aer2 - DJF 1991/92

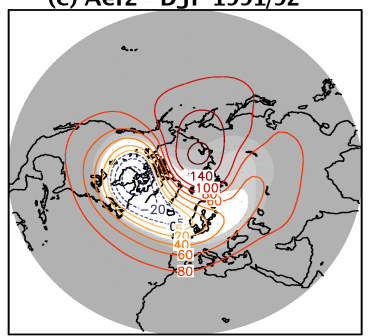

(e) Aer3 - DJF 1991/92

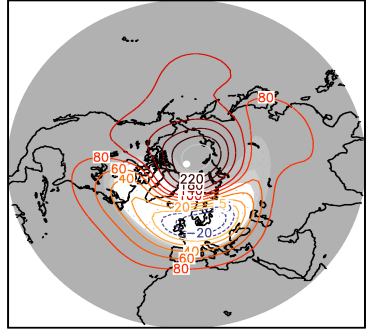

(g) Ocean - DJF 1991/92

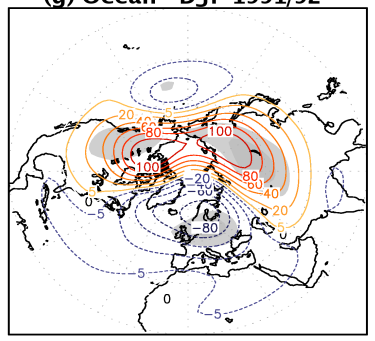

(i) QBO - DJF 1991/92

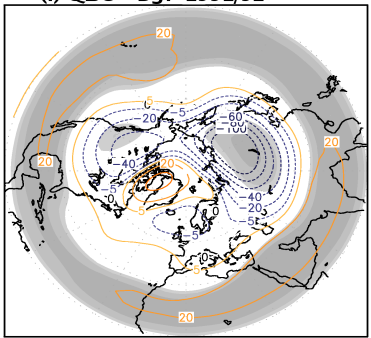

(b) Aer1 - DJF 1992/93

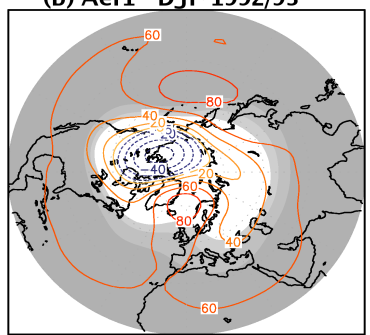

(d) Aer2 - DJF 1992/93

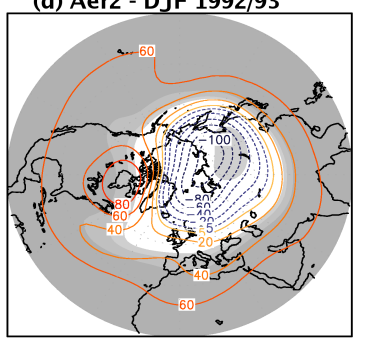

(f) Aer3 - DJF 1992/93

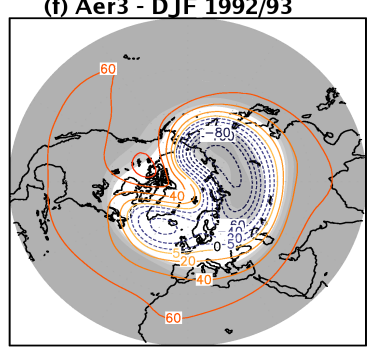

(h) Ocean - DJF 1992/93

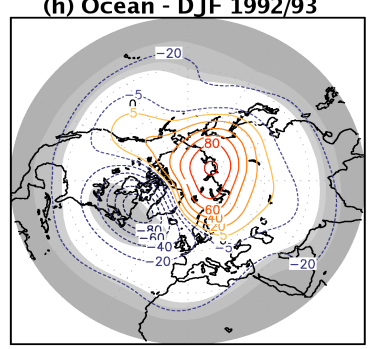

(j) QBO - DJF 1992/93

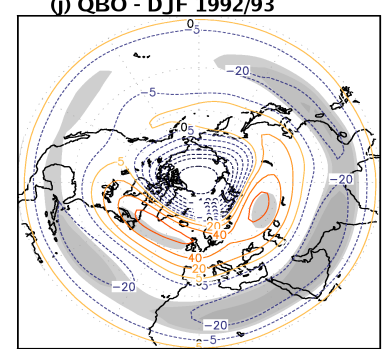

(k) OQ - DJF 1991/92

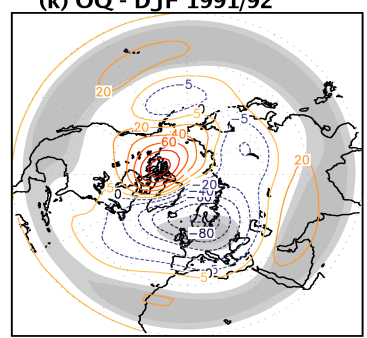

(m) AO - DJF 1991/92

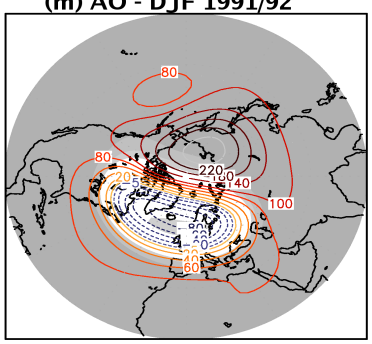

(o) AQ - DJF 1991/92

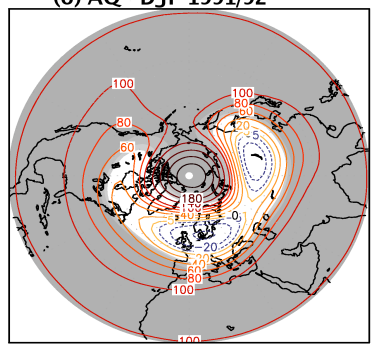

(q) AOQ - DJF 1991/92

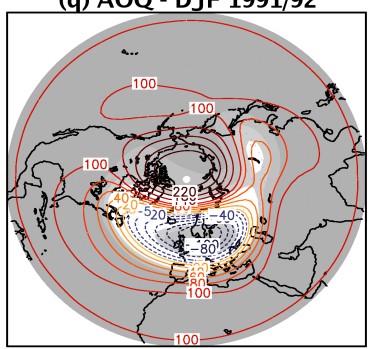

(s) DJF 91/92 - ERA40

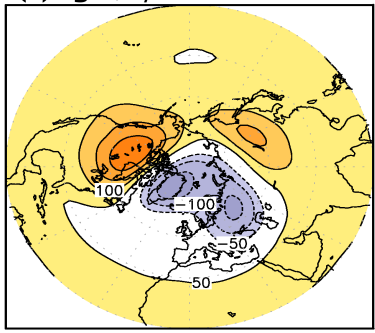

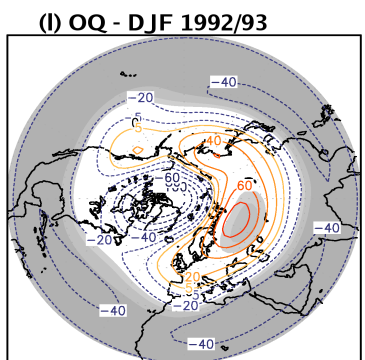

(n) AO - DJF 1992/93

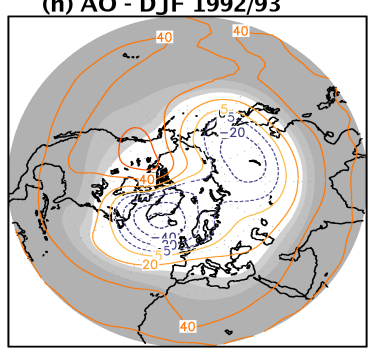

(p) AQ - DJF 1992/93

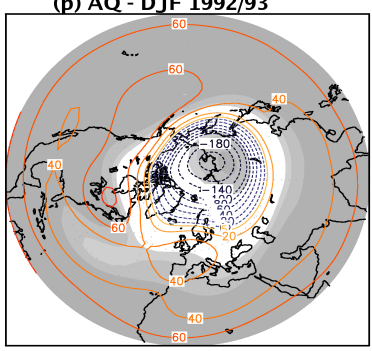

(r) AOQ - DJF 1992/93

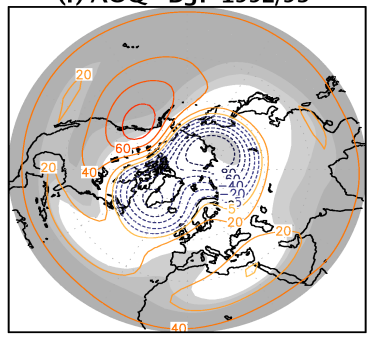

(t) DJE 92/93 - ERA40

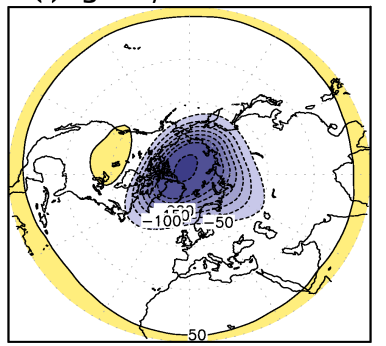

Fig. 4. Geopotential height anomalies at $30 \mathrm{hPa}(m)$ for Aer1 (a, b); Aer2 (c, d); Aer3 (e, f); ocean response (g, h); qbo response (i, j); combined ocean and qbo (OQ) (k, l); combined aerosol and ocean (AO) (m, n); combined aerosol and QBO (AQ) (o, p); combined aerosol, ocean and QBO (AOQ) (q, r); for DJF 1991/92 (left column) and DJF 1992/93 (right column). Heavily shaded areas are significant at 99\% level, lightly shaded at $90 \%$ significance level. Observed $30 \mathrm{hPa}$ geopotential height response from ERA-40 (m) for DJF $1991 / 92(\mathbf{s})$ and DJF 1992/93 (t). Contours are at $20 \mathrm{~m}$ intervals in the model simulations and at $50 \mathrm{~m}$ intervals in the ERA-40 observations. The projection spans from 10 to $90^{\circ} \mathrm{N}$ latitudinally. 

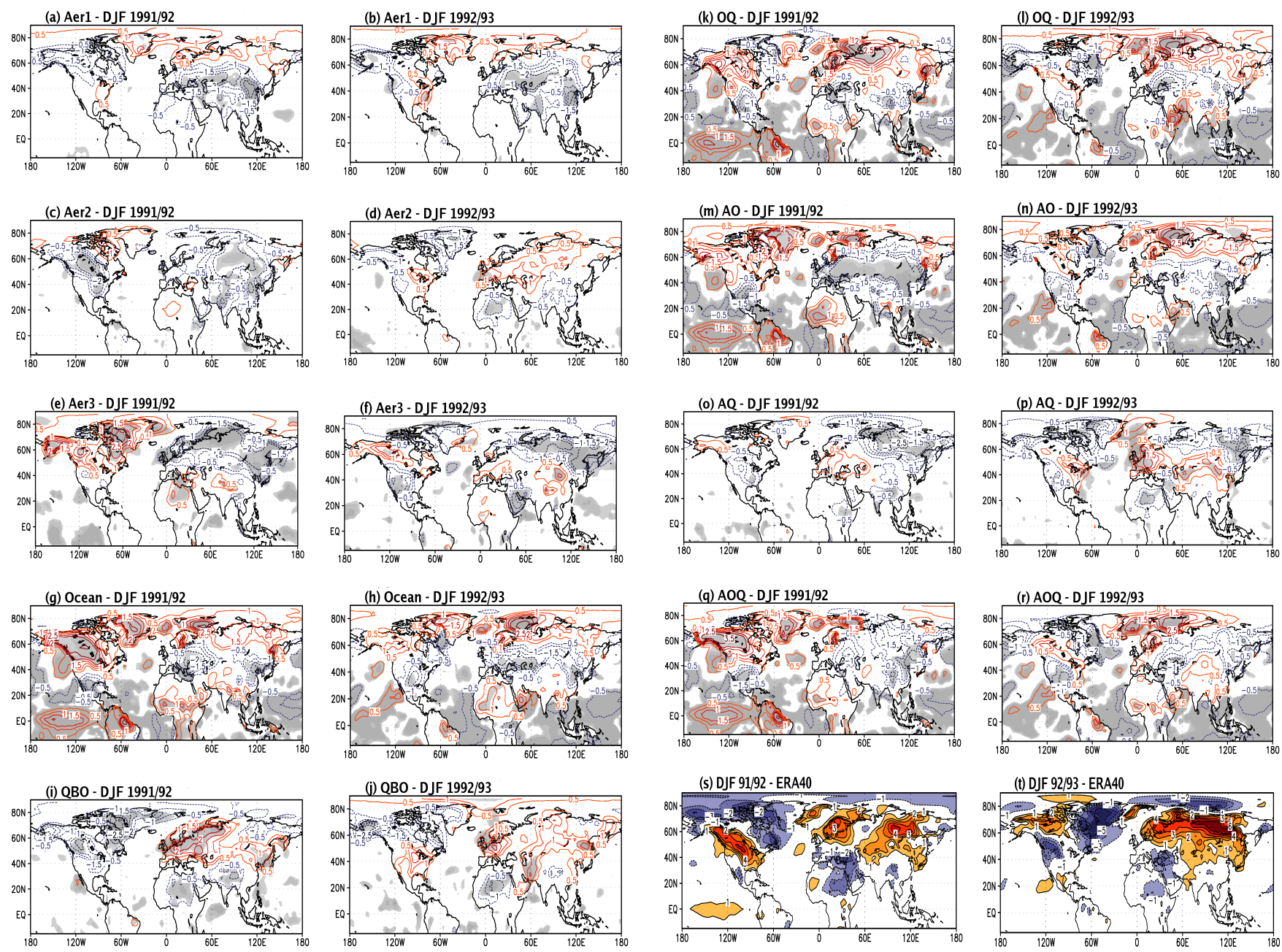

Fig. 5. $2 \mathrm{~m}$ temperature anomalies $(K)$ for Aer1 (a, b); Aer2 (c, d); Aer3 (e, f); ocean response (g, h); qbo response (i, j); combined ocean and qbo (OQ) (k, l); combined aerosol and ocean (AO) (m, n); combined aerosol and QBO (AQ) (o, p); combined aerosol, ocean and QBO (AOQ) (q, r); for DJF 1991/92 (left column) and DJF 1992/93 (right column). Heavily shaded areas are significant at 99\% level, lightly shaded at $90 \%$ significance level. Observed $2 \mathrm{~m}$ temperature response from ERA-40 for DJF 1991/92 (s) and DJF $1992 / 93$ (t). The y-axis shows the latitudinal extend from $15^{\circ} \mathrm{S}$ to $90^{\circ} \mathrm{N}$. The contours are at $0.5 \mathrm{~K}$ intervals for the model simulations and at $1 \mathrm{~K}$ intervals for the observations.

the second winter of AQ response, the polar vortex is more stable (Fig. 4p). This may be because, the westerly shear of the QBO favors a polar vortex with values reaching as low as $220 \mathrm{~m}$. With all the effects included, the model simulates the deepening of the geopotential height anomaly in the second winter, though the magnitudes are relatively weak (around $-100 \mathrm{~m}$ ). It should be noted that the polar vortex was much weaker after the first winter following Mt. Pinatubo eruption compared to the second winter when the vortex was deeper (Fig. 4s and $\mathrm{t}$ ). This study suggests that there is significant non-linearity between aerosol and QBO effects and the strengthening of the polar vortex is more effective when the $\mathrm{QBO}$ is in the westerly phase.

\section{$4.32 \mathrm{~m}$ temperature response}

Stratospheric sulfate aerosol particles from strong tropical volcanic eruptions produce significant warming in the lower equatorial stratosphere thereby increasing the equator to pole temperature gradient in the lower stratosphere of the winter hemisphere. This forces a positive phase of the Arctic Oscillation during northern winter and as a dynamical response produces a winter warming pattern at the surface (Stenchikov et al., 2002). This pattern is manifested as a prominent warming over Northern and Eastern Europe and Siberia and cooling over Greenland, Middle East and Mediterranean. This is presented in the Fig. $5 \mathrm{~s}$ and $\mathrm{t}$, respectively, for the first and second winters following the Mt. Pinatubo eruption, where warming of up to $3-5 \mathrm{~K}$ are observed over N. Europe and 
Siberia and cooling up to $-5 \mathrm{~K}$ is observed over Greenland and up to $-2 \mathrm{~K}$ over the Middle East and the Meditteranean. This feature is typical of low latitude volcanic eruptions of the explosive type (Oman et al., 2005).

Figure 5a-r shows the ensemble mean surface temperature anomalies for two winters following the Pinatubo eruption. The shading in the figures corresponds to the level of significance. Areas with significance level at $95 \%$ are heavily shaded and at $90 \%$ lightly shaded.

For the two winters following the eruption, the warming over northern Europe and Siberia is weakly simulated by the model with climatological SST as boundary conditions (Aer1) (Fig. 5a and b) and is shifted further north, but the anomalies are not significant. The cooling over the Middle East and Meditteranean is simulated by the model in the Aer1 experiments reasonably well, though the magnitudes are over-estimated. With observed SST as boundary conditions (Fig. 5c), the aerosol response cannot reproduce the volcanic winter pattern during the first winter. This may be because of El Niño that is present during the first winter and the signal is stronger than the effects due to the volcanic aerosols. However, the volcanic winter pattern is weakly simulated in the second winter (Fig. 5d), but they are not statistically significant. With both observed SST and QBO effects, the aerosol response show significant cooling over Eurasia. Hence, we can conclude that model is not able to reproduce the observed volcanic winter pattern in the ensemble means with respect to the volcanic radiative forcing alone under the set of boundary conditions considered here.

The individual responses to El Niño SST in the winter circulation is shown in Fig. $5 \mathrm{~g}$ and $\mathrm{h}$. The warm anomalies associated with El Niño over the Eastern Pacific are clearly seen in the ocean response alone experiments (Fig. $5 \mathrm{~g}$ and h) which is expected as the SST in this case is prescribed from observations. The ENSO-related warming over central and northern North America during the winter of 1991/92 is also well simulated by the model. However, statistically significant above normal temperatures are observed beyond north of $60^{\circ} \mathrm{N}$ and cooling over Middle East and parts of Europe and China for both the winters following the eruption. These anomalies are not seen in the observed temperature anomalies in El Niño winters excluding volcanic eruptions (not shown). However, in these experiments, it can only be attributed to the observed SST differences between the observed period and the climatology or to internal variability. It has to be noted that these anomalies are evident in the second winter, when the El Niño effects are negligible.

The QBO effects on the winter circulation of 1991/92 and 1992/93 are presented in Fig. 5i and j, respectively. Significant warming over Europe, parts of Russia and over Eastern China and cooling over northern North America, Canada and Greenland is simulated for the two winters. However, the warming is slightly weaker in the second winter. The combined ocean and QBO effects (Fig. 5k-1) produces the spatial patterns to some extend in both the winters and is closest to the observed winter warming, but the magnitude of the anomalies are less than the observed and there is a northward shift.

The AO experiment that accounts for the effects of both aerosol and SST for the two winters are shown in Fig. 5m and $\mathrm{n}$. The patterns associated with ENSO during the first winter is clearly seen in the figures and the interactions between aerosol and ocean seems to be minimal. Comparing the AO-related response with the ocean response, the only difference is that the warming over Eurasia in the first winter is more pronounced in the $\mathrm{AO}$ response and lower temperatures are observed over Greenland in the second winter in the AO response which is typical of volcanic winters. This may be because the ocean response is too strong in the model, thereby, over-riding the effects due to volcanic eruptions. The combined effects of aerosol and QBO in the AQ experiment (Fig. 5o and p) do not reproduce the observed volcanic winter patterns in both winters. Even in the case where all effects, aerosol, ENSO and QBO are included (Fig. 5q and r), the pattern is shifted poleward.

The ensemble mean responses to individual and combined forcings for two $\mathrm{NH}$ winters cannot reproduce the observed warming, though the cooling is simulated fairly well by some of the forcing experiments. One of the possible reasons can be that the model may not have sufficient vertical resolution in the upper troposphere and lower stratosphere to resolve the interactions between troposphere and stratosphere accurately. Our analysis also shows that the ENSO signal is dominating and partly masks the effects due to volcanic forcing. Another reason would be that zonally averaged volcanic forcing and volcanically induced ozone anomalies are used in the model simulations. The omission of the zonal asymmetric component of volcanic forcing and ozone forcing may produce differences in the response. It is shown that the zonally asymmetric component of ozone has an effect on the stratospheric temperature and planetary wave propagation (Gabriel et al., 2007). Although in the mean response, the model cannot simulate the dynamical response correctly, it should be noted that about $30 \%$ of the individual ensemble members for some of the forcing experiments do simulate this response realistically.

\section{Conclusions}

In this paper, the generalized climatic response to the Mt. Pinatubo eruption is investigated. The response of the tropospheric and stratospheric circulation to individual and combined factors such as volcanic forcing, varying SST boundary conditions and different states of the QBO are assessed. This study is important as it provides insights on how the climate responds to the volcanic forcing when either one or more of the boundary conditions are included. This is the first study of this kind that shows clearly the individual and combined effects after Pinatubo eruption. To evaluate 
how well the model simulates these observed impacts, ensembles of perturbed and unperturbed runs are carried out using the middle atmosphere version of ECHAM5 with different boundary conditions and the differences between the several combinations of perturbed and unperturbed runs give the responses to individual and combined forcings by volcanic aerosols, El Niño and the QBO. So, the ensemble mean differences give an idea on how different the responses would be if El Niño was not present or if only the volcanic forcing exists, which otherwise, would have been possible to estimate without these sets of experiments.

Our results can be summarized as follows:

1. The lower stratospheric temperature response to the volcanic forcing in both the tropics and the winter response in the $\mathrm{NH}$ high latitudes is simulated realistically when all the known factors such as the volcanically induced ozone anomalies, the observed SST state and the QBO effects are included.

2. The tropical stratospheric temperature response is linear with respect to the effects of single forcings.

3. The climate response to the pure aerosol forcings in the lower stratospheric temperature in the tropics is insensitive to the boundary conditions.

4. The tropical signature of the easterly and westerly phases of the QBO in stratospheric temperature is simulated realistically in the pure QBO forcing experiments.

5. The ensemble mean effects of individual and combined forcings for two winters following the eruption could not reproduce the warming over northern and Eastern Europe and Siberia and the cooling over Middle East and Greenland, though this pattern was simulated by $30 \%$ of the ensemble members.

6. The simulated winter signatures in surface temperature shows that the response of the atmosphere to the ocean is very strong in the model. It overrides the effects due to the volcanic forcing. The ocean-related response is evident in the combined responses such as AO, OQ and AOQ and this explains the dominance over other effects.

7. Observations show that the volcanic aerosol forcing tends to strengthen the polar vortex irrespective of the QBO phase. Our model simulations tries to capture the polar vortex deepening in the second winter, when the QBO is in its westerly phase in Aer3 response and the combined responses of AQ and AOQ, though the simulated response is weaker compared to the observations. The vortex is disturbed during the first winters due to the enhanced wave propagation in boreal winter that in turn disturbs the vortex. The second part of this paper gives more details on whether the climate response to the volcanic aerosols depends on the phase of the QBO.
The model simulates the stratospheric temperature response to the volcanic aerosols correctly, but, the simulation of the dynamical response still remains a challenge. A recent study by (Stenchikov et al., 2006) showed that also 20th century simulations made for IPCC AR4 could not reproduce the surface winter anomalies after volcanic eruptions. Hence, further investigations are necessary to understand better the difficulties in modelling the surface warming pattern derived from the winters after major volcanic eruptions of the 20th century.

Acknowledgements. Computations were done at the German Climate Computer Center (DKRZ). C. T. is supported by the German Science Foundation DFG grant TI 344/1-1. G. S. was supported by NSF grant ATM-0351280 and NASA grant NNG05GB06G. We would also like to acknowledge ERA-40 project for the data used in this study that was obtained from the ECMWF data server. We are grateful for the helpful comments from the three anonymous reviewers.

Edited by: P. Haynes

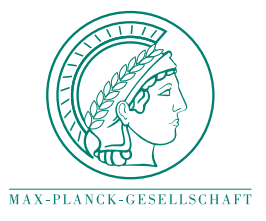

This Open Access Publication is financed by the Max Planck Society.

\section{References}

Baldwin, M. P. and O'Sullivan, D.: Stratospheric effects of ENSO related tropospheric circulation anomalies, J. Climate, 8, 649667, 1995.

Baldwin, M. P. and Dunkerton, T. J.: Propagation of the Arctic Oscillation from the stratosphere to the troposphere, J. Geophys. Res., 104, 30 937-30 946, 1999.

Baldwin, M. P., Gray, L. J., Dunkerton, T. J., Hamilton, K., Haynes, P. H., Randel, W. J., Holton, J. R., Alexander, M. J., Hiorta, I., Horinouchi, T., Jones, D. B. A., Kinnersley, J. S., Marquardt, C., Sato, K., and Takahashi, M.: The quasi-biennial oscillation, J. Geophys. Res., 104, 30 937-30 946, 2001.

Bluth, G. J. S., Doiron, S. D., Schnetzler, S. C., Krueger, A. J., and Walter, L. S.: Global tracking of the $\mathrm{SO}_{2}$ clouds from the June 1991 Mount Pinatubo eruptions, Geophys. Res. Lett., 19, 151154, 1992.

Cagnazzo, C., Manzini, E., Giorgetta, M. A., Forster, P. M. De F., and Morcrette, J. J.: Impact of an improved shortwave radiation scheme in the MAECHAM5 General Circulation Model, Atmos. Chem. Phys., 7, 2503-2515, 2007, http://www.atmos-chem-phys.net/7/2503/2007/.

Chen, W., Takahashi, M., and Graf, H.-F.: Interannual variations of stationary planetary wave activity in the northern winter troposphere and stratosphere and their relations to NAM and SST, J. Geophys. Res., 108, 4797, doi:10.1029/2003JD003834, 2003.

Christiansen, B.: Volcanic eruptions, large-scale modes in the Northern Hemisphere, and the El Niño-Southern Oscillation, J. Climate, 21, 910-922, 2008. 
Dutton, E. G. and Christy, J. R.: Solar radiative forcing at selected locations and evidence for global lower tropospheric cooling following the eruption of El Chichón and Pinatubo, Geophys. Res. Lett., 19, 2313-2316, 1992.

Fortuin, J. P. F. and Kelder, H.: An ozone climatology based on ozonesonde and satellite measurements, J. Geophys. Res., 103, 31 709-31 734, 1998.

Fouquart, Y. and Bonnel, B.: Computations of solar heating of the earth's atmosphere: A new parameterization, Contrib. Atmos. Phys., 53, 35-62, 1980.

Gabriel, A., Peters, D., Kirchner, I., and Graf, H.-F.: Effect of zonally asymmetric ozone on stratospheric temperature and planetary wave propagation, Geophys. Res. Lett., 34, L06807, doi:10.1029/2006GL028998, 2007.

Garcia-Herrera, R., Calvo, N., Garcia, R. R., and Giorgetta, M. A.: Propagation of ENSO temperature signals into the middle atmosphere: A comparison of two general circulation models and ERA-40 reanalysis data, J. Geophys. Res., 111, D06101, doi:10.1029/2005JD006061, 2006.

Gates, W. L.: AMIP: The Atmospheric Model Intercomparison Project, B. Am. Meteorol. Soc., 73, 1962-1970, 1992.

Giorgetta, M. and Bengtsson, L.: The potential role of the quasibiennial oscillation in the stratosphere-troposphere exchange as found in water vapor in general circulation model experiments, J. Geophys. Res., 104, 6003-6019, 1999.

Graf, H.-F., Li, Q., and Giorgetta, M. A.: Volcanic effects on climate: revisiting the mechanisms, Atmos. Chem. Phys., 7, 45034511, 2007, http://www.atmos-chem-phys.net/7/4503/2007/.

Grainger, R. G., Lambert, A., Taylor, F. W., Remedios, J. J., Rogers, C. D., and Corney, M.: Infrared absorption by volcanic stratospheric aerosols observed by ISAMS, Geophys. Res. Lett., 20, 1287-1290, 1993.

Hamilton, K.: An examination of observed Southern Oscillation effects in the Northern Hemisphere stratosphere, J. Atmos. Sci., 50, 3468-3473, 1993.

Hansen, J., Lacis, A., Ruedy, R., and Sato, M.: Potential climate impact of Mt. Pinatubo eruption, Geophys. Res. Lett., 19, 215218, 1992.

Hansen, J., Ruedy, R., Sato, M., and Reynolds, R.: Global surface air temperature in 1995, return to pre-Pinatubo level, Geophys. Res. Lett., 23, 1665-1668, 1996.

Holasek, R. E., Self, S., and Woods, A. W.: Satellite observations and interpretation of the 1991 Mount Pinatubo eruption plumes, J. Geophys. Res., 101, 27 635-27 655, 1996.

Holton, J. R. and Tan, H.-C.: The influence of the equatorial quasibiennial oscillation on the global circulation at $50 \mathrm{mb}$, J. Atmos. Sci., 37, 2200-2208, 1980.

Holton, J. R. and Tan, H.-C.: The quasi biennial oscillation in the Northern Hemisphere lower stratosphere, J. Meteorol. Soc. Jpn., 60, 140-148, 1982.

Holton, J. R.: The role of gravity waves induced drag and diffusion on the momentum budget of the mesosphere, J. Atmos. Sci., 40, 2497-2507, 1982.

Jones, P. D., Moberg, A., Osborn, T. J., and Briffa, K. R.: Surface climate responses to explosive volcanic eruptions seen in long European temperature records and mid-to-high latitude treering density around the Northern Hemisphere, Volcanism and the Earth's atmosphere, in: Geophys. Monogr. Ser., 139, edited by:
Robock, A. and Oppenheimer, C., 239-254, AGU Washington, D.C., 2003.

Kirchner, I., Stenchikov, G. L., Graf, H.-F., Robock, A., and Antuna, J. C.: Climate model simulation of winter warming, summer cooling following the 1991 Mount Pinatubo volcanic eruption, J. Geophys. Res., 104, 19039-19 055, 1999.

Kodera, K.: Influence of volcanic eruptions on the troposphere through stratospheric dynamical processes in the northern hemisphere winter, J. Geophys. Res., 99, 1273-1282, 1994.

Long, C. S. and Stowe, L. L.: Using the NOAA/AVHRR to study stratospheric aerosol optical thicknesses following Mt. Pinatubo eruption, Geophys. Res. Lett., 21, 2215-2218, 1994.

Lynch, J. S. and Stephens, G.: Mount Pinatubo - A satellite perspective of the June 1991 eruptions, in: Fire and Mud - eruptions and lahars of Mount Pinatubo, Philippines, edited by: Newhall, C. G. and Punongbayan, R. S., Philippines Institute of Volcanology and Seismology and University of Washington Press, Quezon City and Seattle, 637-645, 1996.

Manzini, E., Giorgetta, M. A., Esch, M., Kornblueh, L., and Roeckner, E.: The influence of sea surface temperatures on the northern winter stratosphere: Ensemble simulations with the MAECHAM5 model, J. Climate, 19, 3863-3881, 2006.

Matsuno, T.: Vertical propagation of stationary planetary waves in the winter Northern Hemisphere, J. Atmos. Sci., 27, 871-883, 1970.

McCormick, M. P. and Veiga, R. E.: SAGE II measurements of early Pinatubo aerosols, Geophys. Res. Lett., 19, 155-158, 1992.

Minnis, P., Harrison, E. F., Stowe, L. L., Gibson, G. G., Denn, F. M., Doelling, D. R., and Smith Jr., W. L.: Radiative climate forcing by the Mount Pinatubo eruption, Science, 259, 1411-1415, 1993.

Mlawer, E. J., Taubman, S., Brown, P. D., Iacono, M. J., and Clough, S. A.: Radiative transfer for inhomogeneous atmospheres: RRTM, a validated correlated-k model for the longwave, J. Geophys. Res., 102, 16 663-16682, 1997.

Morcrette, J. J., Clough, S. A., Mlawer, E. J., and Iacono, M. $\mathrm{J}$.: Impact of a validated radiative transfer scheme, RRTM on the ECMWF model climate, 10-day forecasts, ECMWF Tech. Memo. 252, ECMWF, Reading, UK, 47 pp., 1998.

Oman, L., Robock, A., Stenchikov, G., Schmidt, G. A., and Ruedy, R.: Climatic response to high latitude volcanic eruptions, J. Geophys. Res., 110, D13103, doi:10.1029/2004JD005487, 2005.

Perlwitz, J. and Graf, H.-F.: The statistical connection between tropospheric and stratospheric circulation of the Northern Hemisphere in winter, J. Climate, 8, 2281-2295, 1995.

Punge, H. J. and Giorgetta, M. A.: Net effect of the QBO in a chemistry climate model, Atmos. Chem. Phys., 8, 6505-6525, 2008, http://www.atmos-chem-phys.net/8/6505/2008/.

Ramachandran, S., Ramaswamy, V., Stenchikov, G. L., and Robock, A.: Radiative impact of the Mount Pinatubo volcanic eruption: Lower stratospheric response, J. Geophys. Res., 105, 24 409-24 429, 2000.

Randel, W. J., Wu, F., Russell III, J. M., Waters, J. W., and Froidevaux, L.: Ozone, temperature changes in the stratosphere following the eruption of Mount Pinatubo, J. Geophys. Res., 100, 16753-16 764, 1995.

Rind, D., Balachandran, N. K., and Suozzo, R.: Climate change and the middle atmosphere. Part II, The impact of volcanic aerosols, J. Climate, 5, 189-208, 1992.

Robock, A. and Mao, J.: Winter warming from large volcanic erup- 
tions, Geophys. Res. Lett., 19, 2405-2408, 1992.

Robock, A. and Mao, J.: The volcanic signal in surface temperature observations, J. Climate, 8, 1086-1103, 1995.

Robock, A.: Cooling following large volcanic eruptions corrected for the effect of diffuse radiation on tree rings, Geophys. Res. Lett., 32, L06702, doi:10.1029/2004GL022116, 2005.

Sassi, F., Kinnison, D., Boville, B. A., Garcia, R. R., and Roble, R.: Effect of El Niño-Southern Oscillation on the dynamical, thermal, chemical structure of the middle atmosphere, J. Geophys. Res., 109, D17108, doi:10.1029/2003JD004434, 2004.

Sato, M., Hansen, J. E., McCormick, M. P., and Pollack, J. B.: Stratospheric aerosol optical depths, 1850-1990, J. Geophys. Res., 98, 22 987-22 994, 1993.

Stenchikov, G., Kirchner, I., Robock, A., Graf, H.-F., Antuna, J. C., Grainger, R. G., Lambert, A., and Thomason, L.: Radiative forcing from the 1991 Mount Pinatubo volcanic eruption, J. Geophys. Res., 103, 13 837-13 857, 1998.

Stenchikov, G., Robock, A., Ramaswamy, V., Schwarzkopf, M. D., Hamilton, K., and Ramachandran, S.: Arctic Oscillation response to the 1991 Mount Pinatubo eruption: Effects of volcanic aerosols, ozone depletion, J. Geophys. Res., 107, 1-16, 2002.

Stenchikov, G., Hamilton, K., Stouffer, R. J., Robock, A., Ramaswamy, V., Santer, B., and Graf, H.-F.: Arctic Oscillation response to volcanic eruptions in the IPCC AR4 climate models, J. Geophys. Res., 111, D07107, doi:10.1029/2005JD006286, 2006.

Stommel, H. and Stommel, E.: Volcano Weather - The story of 1816, the Year Without Summer, Seven Seas Press, Newport, R.I., 177 pp., 1983.

Tanre, D., Geleyn, J.-F., and Slingo, J. M.: First results of the introduction of an advanced aerosol-radiation interaction in the ECMWF low resolution global model, Aerosols and Their Climatic Effects, 133-177, 1984.
Thomas, M. A.: Simulation of the climate impact of Mt. Pinatubo eruption using ECHAM5, PhD thesis, University of Hamburg, Reports on Earth System Science, 52 pp., 2007.

Thomas, M. A., Giorgetta, M. A., Timmreck, C., Graf, H.-F., and Stenchikov, G.: Simulation of the climate impact of Mt. Pinatubo eruption using ECHAM5 - Part 2: Sensitivity to the phase of the QBO, Atmos. Chem. Phys. Discuss., 8, 9239-9261, 2008, http://www.atmos-chem-phys-discuss.net/8/9239/2008/.

Thompson, D. W. J. and Wallace, J. M.: The Arctic Oscillation signature in the wintertime geopotential height and temperature fields, Geophys. Res. Lett., 25, 1297-1300, 1998.

Timmreck, C., Graf, H.-F., and Kirchner, I.: A one and a half year interactive MAECHAM4 simulation of Mount Pinatubo aerosol, J. Geophys. Res., 104, 9337-9359, 1999.

Timmreck, C., Graf, H.-F., and Steil, B.: Aerosol chemistry interactions after the Mt. Pinatubo eruption, Volcanism and the Earth's Atmosphere, AGU Monograph, 139, 213-225, 2003.

Uppala, S. M., Kallberg, P. W., Simmons, A. J., Andrae, U., da Costa Bechtold, V., Fiorino, M., Gibson, J. K., Haseler, J., Hernandez, A., Kelly, G. A., Li, X., Onogi, K., Saarinen, S., Sokka, N., Allan, R. P., Andersson, E., Arpe, K., Balmaseda, M. A., Beljaars, A. C. M., van de Berg, L., Bidlot, J., Bormann, N., Caires, S., Chevallier, F., Dethof, A., Dragosavac, M., Fisher, M., Fuentes, M., Hagemann, S., Holm, E., Hoskins, B. J., Isaksen, L., Janssen, P. A. E. M., Jenne, R., McNally, A. P., Mahfouf, J.-F., Morcrette, J.-J., Rayner, N. A., Saunders, R. W., Simon, P., Sterl, A., Trenberth, K. E., Untch, A., Vasiljevic, D., Viterbo, P., and Woollen, J.: The ERA-40 re-analysis, Q. J. Roy. Meteor. Soc., 131, 2961-3012, 2005. 